\title{
Effects of JNJ-54452840, an Anti- $\beta 1$ Receptor Antibody Cyclopeptide in Heart Failure Patients: A Randomized, Double-blind, Parallel-group, Phase-2 Pilot Study
}

Stefan Störk ${ }^{*}$, Alexei N Plotnikov², Gary Peters², Brian E Davies², Ivo Nnane², David Rivas², Fisseha Tesfaye², Stefan Kääb, ${ }^{3,4}$ Axel Bauer $^{3}$, Andreas Luchner ${ }^{5}$, Martin Ungerer ${ }^{6}$, Roland Jahns ${ }^{1,7}$, Martin Lohse ${ }^{1,8}$ and Georg ErtI ${ }^{1}$

${ }^{1}$ Comprehensive Heart Failure Center (CHFC), University of Würzburg, and Medical Department I, University Hospital Würzburg, Germany

${ }^{2}$ Janssen Research and Development, LLC, New Jersey, USA

${ }^{3}$ Department of Medicine I-Cardiology, Ludwig-Maximillian's University Hospital, Munich, Germany

${ }^{4}$ DZHK (German Centre for Cardiovascular Research), partner site Munich Heart Alliance, Munich, Germany

${ }^{5}$ Department of Internal Medicine III - Cardiology, University of Tübingen, Germany

${ }^{6}$ AdvanceCor GmbH (formerly Procorde), Martinsried, Germany

${ }^{7}$ CHFC and Interdisciplinary Bank of Biomaterials and Data Würzburg, University Hospital of Würzburg, Germany

${ }^{8}$ Rudolf Virchow Center / DFG Research Center for Experimental Biomedicine, Würzburg, Germany

\begin{abstract}
Aim: JNJ-54452840 (COR-1) is a novel investigational cyclopeptide with proposed mechanism of action that decreases circulating anti- $\beta_{1}$-adrenergic receptor antibodies (anti- $\beta_{1}$-Abs) in heart failure patients. In a phase-2, double-blind, placebo-controlled pilot study, effects of JNJ-54452840 were investigated on cardiac function at rest in patients with Dilated Cardiomyopathy (DCM) when administered in addition to guideline-recommended heart failure therapy versus 6-months of guideline-recommended therapy alone.
\end{abstract}

Methods: Patients with DCM and circulating anti- $\beta_{1}$-Abs received treatment with placebo or JNJ-54452840 (6 doses of 20,80 or $160 \mathrm{mg}$ administered intravenously every 4 weeks) in addition to guideline-recommended heart failure therapy.

Results: Thirty-six patients (Caucasian, mean age 59.6 years, mean LVEF $32 \%$ ) were enrolled. An increase $(+5.4 \%)$ in centrally-assessed Left Ventricular Ejection Fraction (LVEF) was observed in $80 \mathrm{mg} \mathrm{JNJ}-54452840$ group compared to a decrease $(-1.6 \%)$ in the placebo group (primary efficacy endpoint). Among secondary efficacy endpoints, locally-assessed LVEF values were similar to primary results, suggesting lack of treatment effect from baseline to month 9 . NT-proBNP values varied considerably between patients but were not significantly improved in JNJ-54452840-treated groups versus placebo. Compared to baseline, both JNJ-54452840 and placebo groups demonstrated a numerical increase in 6 -minute walk test from baseline to month 6 . The most common adverse events reported among JNJ-54452840-treated patients were cardiac failure and nasopharyngitis $(n=4$ each), and cough, sinusitis, increased heart rate ( $n=3$ each).

Conclusion: Considering that this phase 2 trial, originally planned to recruit 160 patients was amended to a pilot study for strategic reasons, no definitive statements on the efficacy of JNJ-5445280 in DCM patients with circulating anti- $\beta_{1}$-Abs can be made, although centrally-assessed LVEF appeared to improve in the $80 \mathrm{mg}$ dose group. No compound-related safety or tolerability signals were observed.

\section{Introduction}

Dilated Cardiomyopathy (DCM) is one of the major pathophysiological conditions causing cardiac chamber dilatation and left ventricular remodelling, often resulting in heart failure [1]. In the Western population, annual incidence of DCM amounts to 100 patients/million, and is prevalent in 400 patients/million [1]. In the end-stage, its clinical management requires surgical procedures such as the implantation of cardiac assist devices or heart transplantation.

Stimulating anti- $\beta$ - 1 -adrenergic receptor autoantibodies (anti- $\beta_{1}-$ Abs) have been reported to play an important role in the pathogenesis of DCM, while their prevalence in DCM patients (range: $26-60 \%$ ) may portend a poor prognosis [2,3]. Anti- $\beta_{1}$-Abs are considered negative prognostic markers that have been shown to be associated with a greater reduction in left ventricular function $[3,4]$, and an increase in the prevalence of serious ventricular arrhythmias [3,5], sudden cardiac death [5], and cardiovascular mortality [3,6]. Therefore, development of new therapeutic strategies that potentially neutralize these autoantibodies may provide a viable alternative for the treatment of heart failure [7-9].
JNJ-54452840 is a novel cyclic peptide with a proposed method of action of binding to circulating anti- $\beta_{1}$-Abs. Preclinical studies using a rat model of immune cardiomyopathy provided evidence for the capability of JNJ-54452840 to reverse anti- $\beta 1$-Ab-induced myocardial damage after 6 months of JNJ-54452840 administration every 4 weeks [10]. JNJ-54452840 is in development for intravenous once-monthly administration as an addition to guideline-recommended treatment regimens for heart failure. As such, it represents an innovative option in

*Corresponding author: Prof.r. Stefan Störk, MD PhD, Comprehensive Heart Failure Center, University of Würzburg, Straubmühlweg 2a, D-97078 Würzburg, Germany, Tel: ++49 931201 46266; Fax: ++49 931201646362 ; E-mail: stoerks@ukw.de

Received July 22, 2016; Accepted July 27, 2016; Published August 01, 2016

Citation: Störk S, Plotnikov AN, Peters G, Davies BE, Nnane I, et al. (2016) Effects of JNJ-54452840, an Anti- 11 Receptor Antibody Cyclopeptide in Heart Failure Patients: A Randomized, Double-blind, Parallel-group, Phase-2 Pilot Study. Cardiovasc Pharm Open Access 5: 190. doi:10.4172/2329-6607.1000190

Copyright: ( 2016 Störk S, et al. This is an open-access article distributed under the terms of the Creative Commons Attribution License, which permits unrestricted use, distribution, and reproduction in any medium, provided the original author and source are credited. 
Citation: Störk S, Plotnikov AN, Peters G, Davies BE, Nnane I, et al. (2016) Effects of JNJ-54452840, an Anti- $\beta 1$ Receptor Antibody Cyclopeptide in Heart Failure Patients: A Randomized, Double-blind, Parallel-group, Phase-2 Pilot Study. Cardiovasc Pharm Open Access 5: 190. doi:10.4172/2329-6607.1000190

Page 2 of 8

personalized medicine for treating a subgroup of patients with circulating anti- $\beta_{1}$-Abs. JNJ-54452840 may act through scavenging of anti- $\beta_{1}-A b s$ in the circulating blood directly after injection, while also reducing the $\beta_{1}$-ARspecific memory-B cell population responsible for anti- $\beta 1-\mathrm{Ab}$ production but not interfering with overall $\mathrm{B}$ cell function $[11,12]$.

A phase 1, placebo-controlled clinical study in healthy volunteers demonstrated that the administration of JNJ-54452840 was safe and well-tolerated, while the plasma of these study-participants dosedependently decreased $\beta_{1}$-AR binding of standardized test plasma samples containing anti- $\beta_{1}$-AR Abs [12]. The concentration of JNJ54452840 increased linearly with dose, the clearance was rapid, and half-life was limited (3.1 to 3.4 minutes), while the emergence of anti$\beta 1$-Abs was not observed [12].

The objective of the current phase 2, double-blind study was to investigate the effects on cardiac function of a 6 months-treatment with intravenous JNJ-54452840 in addition to guideline-recommended heart failure therapy compared to guideline-recommended therapy alone in heart failure patients with DCM and circulating anti- $\beta_{1}-$ Abs. This phase 2-study, originally planned to recruit 160 patients, was amended to a pilot study by the sponsor (Janssen Research \& Development, LLC) for strategic reasons, and not because of any medical concerns.

\section{Methods}

\section{Patients}

Men or women aged between 18-75 years with a diagnosis of heart failure due to DCM (for at least 1-8 years before screening), New York Heart Association class II/III, Left Ventricular Ejection Fraction (LVEF) $<=45 \%$ assessed on biplane echocardiography, and circulating anti- $\beta_{1}$-Abs were recruited into the study. Patients received recommended guideline-recommended heart failure therapy including angiotensin converting enzyme inhibitors or angiotensin II receptor blockers, $\beta$-blockers, and mineralocorticoid receptor antagonists according to European Society of Cardiology guidelines [11] for at least 6 months and at a stable dose for at least 2 months prior to screening. Exclusion criteria included a history of ischemic heart disease ( $\geq 50 \%$ coronary artery stenosis) and/or myocardial infarction (assessed by coronary angiography), $\geq 3^{\text {rd }}$ degree valvular defect, and any disease requiring immunosuppressive treatment with the exception of prednisone $\leq 5 \mathrm{mg}$ /day.

The protocol was reviewed and approved by the ethics committee of the Medical Faculty Würzburg (Germany, No.17/11_ff 2012/300) and informed consent was obtained from each patient before enrolment. The study was conducted according to the Declaration of Helsinki, Good Clinical Practice guidelines, and other applicable regulatory requirements.

\section{Study design and treatment}

This was a phase 2 , randomized, double-blind, placebo-controlled, parallel-group, multi-center pilot study of approximately 9 months duration: screening up to 14 days; double-blind treatment period of 6 months including end-of-study (month 6); and follow-up periods (4 [ \pm 1$]$ months after last dose and $12[ \pm 1]$ months after treatment completion). Patients were randomized 1:1:1:1 to 1 of 4 treatment groups: guideline-recommended therapy plus placebo $(0.9 \% \mathrm{NaCl}$ solution) or guideline-recommended therapy plus $20 \mathrm{mg}, 80 \mathrm{mg}$, or $160 \mathrm{mg} \mathrm{JNJ}-54452840$ administered intravenously every 4 weeks for total 6 doses. Three stratification factors with two levels each were utilised: gender, level of anti- $\beta_{1}$-Abs (low vs. high), and LVEF ( $\leq 25 \%$ vs. $>25$ to $\leq 45 \%$ )

\section{Study evaluations}

Efficacy analyses: The primary efficacy endpoint was the change from baseline to month 6 in LVEF, assessed using biplane echocardiography (central assessment at baseline and month 6). Exploratory analyses included a categorical analysis for the change from baseline in central LVEF $\geq 5 \%$, since a $5 \%$ increase in LVEF can be a predictor of improved clinical outcome according to the published literature $[11,13,14]$.

Key secondary endpoints included: change from baseline to month 9 in LVEF using biplane echocardiography (local assessment); change from baseline to month 6 in N-terminal pro-hormone B-type natriuretic peptide (NT-proBNP) values, and change in 6-minute walk test distance from baseline to months 6 and 9.

$\beta 1-A R$ autoantibodies analyses: Anti- $\beta 1$-Abs was determined at baseline and pre-dose at months 1-3, 6, and at month 9 after treatment completion. After administration of the first 3 doses of the study drug, anti- $\beta 1-A b$ levels were regularly (per protocol) monitored in each patient. A cell-based competitive detection-assay was used to determine circulating anti- $\beta 1-\mathrm{Ab}$ levels [15]. Results were expressed as $\%$ inhibition with an adjustment factor for binding of the mouse 23-6-7 monoclonal antibody to human $\beta 1$-ARs expressed in SF9 insect cells; the levels of inhibition were pre-defined as $<10 \%$ for low and $\geq 10 \%$ for high titres of anti- $\beta 1$-Abs. Based on the results of the pre-clinical studies and the first-in-human phase-1 study [12], the pre-specified criterion was established to discontinue treatment if a patient was observed to have evidence of a 3 -fold rise in circulating anti- $\beta 1$-Ab levels.

Pharmacokinetic analyses: Blood samples for measurement of plasma JNJ-54452840 concentrations were collected at predose and at 2, 5, 10, and 60 minutes after the first (month 1) and last (month 5) JNJ-54452840 administration for selected patients (20 mg [n=2], $80 \mathrm{mg}$ [n=3], and $160 \mathrm{mg}[\mathrm{n}=7])$. A validated, specific, and sensitive ELISA method was used to analyze plasma JNJ-54452840 concentrations. The following Pharmacokinetic (PK) parameters were calculated using non-compartmental methods in Phoenix WinNonlin 6.2.1: area under the concentration-time curve from 0 to the time of last quantifiable concentration $\left(\mathrm{AUC}_{0-\mathrm{t}}\right)$; area under the concentration-time curve from time 0 to infinity with extrapolation of the terminal phase $\left(\mathrm{AUC}_{0-\infty}\right)$; maximum observed concentration $\left(\mathrm{C}_{\max }\right)$; time to $\mathrm{C}_{\max }$ $\left(\mathrm{T}_{\max }\right)$; terminal half-life $\left(\mathrm{T}_{1 / 2}\right)$; total systemic clearance after IV administration [15]; volume of distribution at steady state $\left(\mathrm{V}_{\mathrm{ss}}\right)$; and Mean Residence Time (MRT).

Safety analyses: Safety was assessed throughout the study by monitoring Treatment-Emergent Adverse Events (TEAEs), Serious Adverse Events (SAEs), TEAEs of special interest (bradyarrhythmia and immunogenicity), treatment discontinuation, changes in vital signs, laboratory abnormalities, ECG and echocardiography parameters, and changes in circulating anti- $\beta 1-\mathrm{AR}$ autoantibody levels.

\section{Statistical methods}

For this study, no formal statistical hypothesis testing was performed. Primary and secondary endpoints were assessed using the last observation carried forward or baseline observation carried forward approach, as applicable. Results for efficacy, anti- $\beta 1-A R$ antibody (inhibition percent cut-off adjusted over time), and PK analyses were descriptively summarized.

Sample size determination: A sample size of 160 patients was originally planned assuming $4.5 \%$ mean change in LVEF (guidelinerecommended deviation $[S D]=6.4 \%)$ with $87 \%$ power. For strategic 
Citation: Störk S, Plotnikov AN, Peters G, Davies BE, Nnane I, et al. (2016) Effects of JNJ-54452840, an Anti- 31 Receptor Antibody Cyclopeptide in Heart Failure Patients: A Randomized, Double-blind, Parallel-group, Phase-2 Pilot Study. Cardiovasc Pharm Open Access 5: 190. doi:10.4172/2329-6607.1000190

Page 3 of 8

reasons, the original study was converted to a pilot study instead of the initially-conceived phase 2 study of 160 patients, which would have allowed for a full statistical analysis. Thus, the protocol was amended to modify the design to a pilot study for exploratory analysis only, and therefore the preplanned number of patients was reduced to up to 60 .

Analysis populations: All randomized patients constituted IntentTo-Treat (ITT) population, while the safety population included all patients who had received at least 1 dose of the study drug.

\section{Data analysis in echocardiography core laboratory}

Image analysis was conducted locally and centrally. Local image analysis was undertaken for all echocardiograms and additional central image analysis of selected parameters was performed for echocardiograms recorded at screening and at the month 6 visit. Initially, assessment of patient eligibility at screening was based on local image analysis and confirmed by central analysis. If central image analysis revealed that the LVEF eligibility criterion of a randomized patient had not been met, then the patient was to be excluded from the study. Endpoint analysis was conducted using central image analysis results.

\section{Results}

\section{Patient disposition and demographic characteristics}

In total, 36 patients were enrolled at 4 centres in Germany from 25 October 2011 to 28 August 2013, and were randomized to receive either
$20 \mathrm{mg}(\mathrm{n}=8), 80 \mathrm{mg}(\mathrm{n}=6), 160 \mathrm{mg}(\mathrm{n}=12) \mathrm{JNJ}-54452840$ or placebo $(\mathrm{n}=10)$. The ITT population comprised all randomized 36 patients. Thirty patients received at least one dose of study medication and comprised the safety population; 21 patients from safety population constituted the intended population who had baseline LVEF $\leq 40 \%$ as assessed by the core echo laboratory.

In the ITT population, $17 / 36(47.2 \%)$ patients (placebo [n=6]; combined JNJ-54452840 treatment group $[\mathrm{n}=11]$ ) completed the entire study. Of the treated patients, 9 patients from the combined JNJ-54452840 group $(n=26)$ and 1 patient from the placebo group prematurely discontinued treatment (Figure 1). A significant proportion of patients were excluded because their LVEF was determined to be $>45 \%$ by the (secondary) core lab analysis of echocardiographic registrations. In all of these patients, no medical reasons for the discontinuations were reported.

All patients were Caucasian and predominantly men with a mean age of 59.6 (range 57.5-62.0 years), and a mean LVEF of $32 \%$ (range 29.4-35.4\%) across the treatment groups (Table 1). Due to the small number of randomized patients, the baseline characteristics were minimally imbalanced between the treatment groups: patients in the placebo group compared to the combined JNJ-54452840 treatment groups generally had a longer history of heart failure, more cardiovascular events requiring hospitalizations within the last 3 months before enrolment, and higher NT-proBNP levels, while a relatively minor fraction of patients had diabetes and/or hypertension.

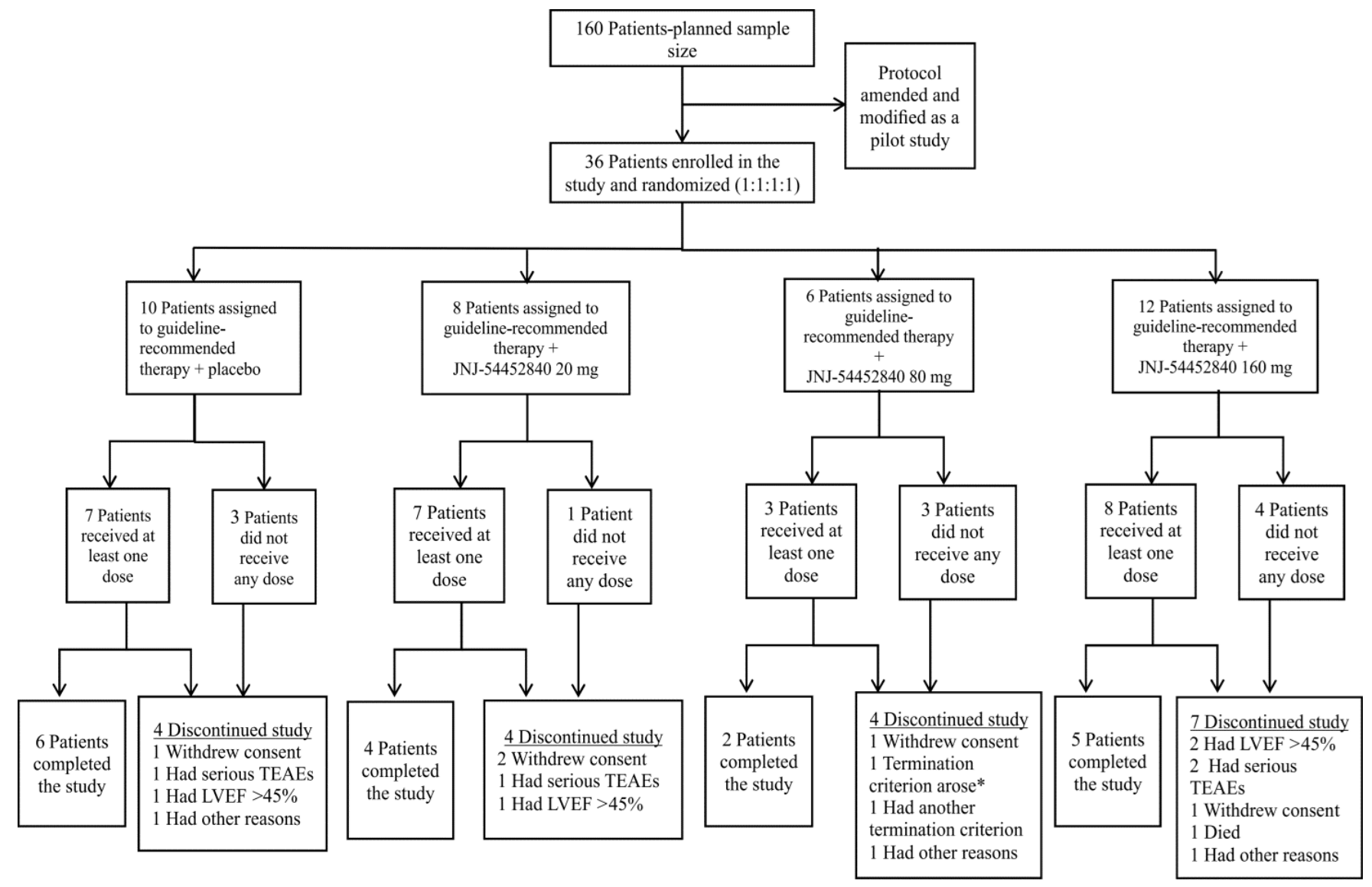

"Renal insufficiency, age and valvular heart disease. LVEF: Left Ventricular Ejection Fraction; TEAE: Treatment Emergent Adverse Event

Figure 1: Patient disposition. 
Citation: Störk S, Plotnikov AN, Peters G, Davies BE, Nnane I, et al. (2016) Effects of JNJ-54452840, an Anti- 31 Receptor Antibody Cyclopeptide in Heart Failure Patients: A Randomized, Double-blind, Parallel-group, Phase-2 Pilot Study. Cardiovasc Pharm Open Access 5: 190. doi:10.4172/2329-6607.1000190

Page 4 of 8

\begin{tabular}{|c|c|c|c|c|c|}
\hline & \multirow{2}{*}{$\begin{array}{l}\text { Placebo } \\
(n=10)\end{array}$} & \multicolumn{4}{|c|}{ JNJ-54452840 } \\
\hline & & $\begin{array}{l}20 \mathrm{mg} \\
(\mathrm{n}=8)\end{array}$ & $\begin{array}{l}80 \mathrm{mg} \\
(\mathrm{n}=6)\end{array}$ & $\begin{array}{l}160 \mathrm{mg} \\
(\mathrm{n}=12)\end{array}$ & $\begin{array}{c}\text { Combined } \\
(n=26)\end{array}$ \\
\hline \multicolumn{6}{|l|}{ Sex } \\
\hline Men & $7(70.0)$ & $6(75.0)$ & $5(83.3)$ & $10(83.3)$ & $21(80.8)$ \\
\hline Women & $3(30.0)$ & $2(25.0)$ & $1(16.7)$ & $2(16.7)$ & $5(19.2)$ \\
\hline Age, years & $59.4(9.6)$ & $57.5(10.9)$ & $62.0(13.6)$ & $59.8(11.9)$ & $59.6(11.6)$ \\
\hline BMI, $\mathbf{k g} / \mathrm{m}^{2}$ & $29.9(7.9)$ & $26.2(3.8)$ & $35.5(8.8)$ & $29.1(5.7)$ & $29.7(6.5)$ \\
\hline HF diagnosis duration, years & $6.01(3.776)$ & $4.31(2.683)$ & $3.68(2.015)$ & $4.95(3.394)$ & $4.46(2.857)$ \\
\hline Hospitalization due to CV within 3 months & $2(20.0)$ & $0(0.0)$ & $0(0.0)$ & $1(8.3)$ & $1(3.8)$ \\
\hline \multicolumn{6}{|l|}{ NYHA } \\
\hline Stage II & $7(70.0)$ & $8(100.0)$ & $3(50.0)$ & $7(58.3)$ & $18(69.2)$ \\
\hline Stage III & $3(30.0)$ & $0(0.0)$ & $3(50.0)$ & $5(41.7)$ & $8(30.8)$ \\
\hline Diabetes & $1(10.0)$ & $1(12.5)$ & $2(33.3)$ & $4(33.3)$ & $7(26.9)$ \\
\hline Hypertension & $2(20.0)$ & $3(37.5)$ & $4(66.7)$ & $4(33.3)$ & $11(42.3)$ \\
\hline Heart rate, bpma & $74.6(7.00)$ & $76.9(10.92)$ & $84.2(11.43)$ & $75.3(8.59)$ & $77.8(10.18)$ \\
\hline NT-proBNP, pg/mla & $5678(9347)$ & $2216(1692)$ & $971(665)$ & $2299(2024)$ & $1971(1723)$ \\
\hline LVEF, $\%^{\mathrm{b}}$ & $35.4(11.7)$ & $29.4(12.1)$ & $35.0(13.4)$ & $32.4(10.8)$ & $32.0(11.4)$ \\
\hline$\leq 25 \%$ at baseline & $1(10.0)$ & $2(25.0)$ & $1(16.7)$ & $2(16.7)$ & $5(19.2)$ \\
\hline$>25 \%$ to $\leq 45$ at baseline & $9(90.0)$ & $7(75.0)$ & $5(83.3)$ & $10(83.3)$ & $21(80.8)$ \\
\hline \multicolumn{6}{|l|}{ Baseline anti- $\beta 1-A R-A b$ value } \\
\hline High & $6(60.0)$ & $4(50.0)$ & $5(83.3)$ & $8(66.7)$ & $17(65.4)$ \\
\hline Low & $4(40.0)$ & $4(50.0)$ & $1(16.7)$ & $4(33.3)$ & $9(34.6)$ \\
\hline \multicolumn{6}{|l|}{ Guideline-recommended therapy } \\
\hline Beta-blocker & $10(100.0)$ & $8(100.0)$ & $6(100.0)$ & $11(91.7)$ & $25(96.2)$ \\
\hline ACE inhibitor & $7(70.0)$ & $4(50.0)$ & $4(66.7)$ & $8(66.7)$ & $16(61.5)$ \\
\hline ARB & $3(30.0)$ & $4(50.0)$ & $1(16.7)$ & $3(25.0)$ & $8(30.8)$ \\
\hline Aldosterone antagonist & $7(70.0)$ & $5(62.5)$ & $4(66.7)$ & $11(91.7)$ & $20(76.9)$ \\
\hline \multicolumn{6}{|l|}{ Device therapy } \\
\hline Pacemaker & $2(20.0)$ & $0(0.0)$ & $1(16.7)$ & $3(25.0)$ & $4(15.4)$ \\
\hline $\begin{array}{l}\text { Implantable cardioverter- } \\
\text { defibrillator }\end{array}$ & $5(50.0)$ & $4(50.0)$ & $5(83.3)$ & $8(66.7)$ & $17(65.4)$ \\
\hline
\end{tabular}

Data are mean $(\mathrm{SD})$ or $\mathrm{n}(\%)$

ACE: Angiotensin Converting Enzyme; AR: Adrenergic Receptor; ARB: Angiotensin II Receptor Blocker; BMI: Body Mass Index; CV: Cardiovascular; HF: Heart Failure; LVEF: Left Ventricular Ejection Fraction; NT-proBNP: N-Terminal pro-hormonent B-type Natriuretic Peptide; NYHA: New York Heart Association; SD: Standard Deviation ${ }^{a} \mathrm{n}=7$ for placebo and $20 \mathrm{mg}, \mathrm{n}=5$ for $60 \mathrm{mg}$ and $\mathrm{n}=10$ for $160 \mathrm{mg}$; ${ }^{\mathrm{b}} \mathrm{n}=9$ for placebo, $\mathrm{n}=8$ for $20 \mathrm{mg}, \mathrm{n}=5 \mathrm{for} 60 \mathrm{mg}$ and $\mathrm{n}=12 \mathrm{for} 160 \mathrm{mg}$

Table 1: Demographic and baseline characteristics (Intent-to-treat population).

The median (25-75 percentile) extent of exposure was 155 (143$156)$ days for the placebo group, and 152 (36-155) days for $20 \mathrm{mg}, 150$ (97-154) days for $80 \mathrm{mg}$, and 100 (1-148) days for $160 \mathrm{mg} \mathrm{JNJ}-54452840$ dose groups.

\section{Efficacy results}

The primary efficacy results demonstrated a reduction in the centrally assessed mean LVEF values of the placebo group, while an increase of approximately $0.9 \%$ was observed among the JNJ-54452840 treatment groups (Table 2A). Similar results were observed for the safety population (data not shown). Two patients ( $\mathrm{n}=1$ each from placebo and $80 \mathrm{mg}$ JNJ-54452840 groups) did not have a central assessment of the echocardiograms (LVEF measurement), while 9 patients (placebo $[\mathrm{n}=2], 20 \mathrm{mg}[\mathrm{n}=1], 80 \mathrm{mg}[\mathrm{n}=2], 160 \mathrm{mg}[\mathrm{n}=4])$ had no centrally assessed LVEF values at month 6. Exploratory analyses demonstrated that at least five patients from the combined JNJ-54452840 group and two patients from the placebo group had a $\geq 5 \%$ increase in central LVEF values from baseline (Table 2A). Overall, no clear treatment effect was observed in this small number of patients.

Secondary efficacy results for LVEF values assessed locally were generally similar to the primary efficacy data, without evidence of a significant treatment effect (Table 2B). A statistically significant increase in mean local LVEF values were observed from baseline to month 1 and to month 3 , followed by decreases after 3 months of treatment in the placebo and JNJ-54452840 (160 mg) groups that were not statistically significant (Figure 2). The $80 \mathrm{mg}$ JNJ-54452840 treatment group demonstrated a numerical increase in mean local LVEF values up to month 6 , followed by a decrease in the time-period thereafter that was not significant. At month 6, mean NT-proBNP values numerically decreased in the placebo group, whereas each of the JNJ-54452840 dose groups demonstrated a numerical increase in mean NT-proBNP values (Table 2B). Except for the $20 \mathrm{mg}$ dose group, the JNJ-54452840 treatment groups and the placebo group demonstrated an increase in the 6-minute walk test distance from baseline to month 6 . At month 9, the JNJ-54452840 $80 \mathrm{mg}$ and $160 \mathrm{mg}$ groups demonstrated a further increase in 6-minute walk test distance compared to baseline, whereas this distance decreased in the placebo and JNJ-54452840 $20 \mathrm{mg}$ groups (data not shown). However, these changes were not significant.

\section{B1-AR autoantibody analysis and JNJ-54452840 levels}

Compared to other dose-groups, patients in the JNJ-54452840 $160 \mathrm{mg}$ group demonstrated a relatively lower mean $( \pm \mathrm{SE})$ percent inhibition over time (Figure 3). However, definitive conclusions cannot be drawn because the assay has not been validated as a quantitative assay. During the study, none of the patients met the predefined treatment discontinuation criterion $(>3$ times increase in circulating anti- $\beta 1-A b$ levels from baseline) and none of the patients were observed to convert from a "positive" to a "negative" autoantibody-status. Few 
Citation: Störk S, Plotnikov AN, Peters G, Davies BE, Nnane I, et al. (2016) Effects of JNJ-54452840, an Anti- $\beta 1$ Receptor Antibody Cyclopeptide in Heart Failure Patients: A Randomized, Double-blind, Parallel-group, Phase-2 Pilot Study. Cardiovasc Pharm Open Access 5: 190. doi:10.4172/2329-6607.1000190

Page 5 of 8

\begin{tabular}{|c|c|c|c|c|c|}
\hline & \multirow{2}{*}{$\begin{array}{l}\text { Placebo } \\
(n=10)\end{array}$} & \multicolumn{4}{|c|}{ JNJ-54452840 } \\
\hline & & $\begin{array}{c}20 \mathrm{mg} \\
(\mathrm{n}=8)\end{array}$ & $\begin{array}{c}80 \mathrm{mg} \\
(\mathrm{n}=6)\end{array}$ & $\begin{array}{c}160 \mathrm{mg} \\
(\mathrm{n}=12)\end{array}$ & $\begin{array}{c}\text { Combined } \\
(n=26)\end{array}$ \\
\hline \multicolumn{6}{|l|}{ Central LVEF, \% } \\
\hline Baseline, mean (SD) & $35.4(11.7)$ & $29.4(12.1)$ & $35.0(13.4)$ & $32.4(10.8)$ & $32.0(11.4)$ \\
\hline Change from baseline, mean (SD)? & $-1.6(5.9)$ & $0.8(5.6)$ & $5.4(10.1)$ & $-0.9(3.1)$ & $0.9(6.0)$ \\
\hline \multicolumn{6}{|l|}{ Central LVEF, $\%$} \\
\hline Change from baseline $<5 \%, n(\%)$ & $7(70.0)$ & $5(62.5)$ & $3(50.0)$ & $12(100.0)$ & $20(76.9)$ \\
\hline \multicolumn{6}{|l|}{ Central LVEF, \% } \\
\hline Change from baseline $\geq \mathbf{5 \%}, \mathrm{n}(\%)$ & $2(20.0)$ & $3(37.5)$ & $2(33.3)$ & $0(0.0)$ & $5(19.2)$ \\
\hline
\end{tabular}

BOCF: Baseline Observation Carried Forward values were used if no further measurements were available; LVEF: Left Ventricular Ejection Fraction.

Table 2A: Changes from baseline to month 6 in primary efficacy endpoint (Intent-to-treat population, BOCF).

\begin{tabular}{|c|c|c|c|c|c|}
\hline & \multirow{2}{*}{$\begin{array}{l}\text { Placebo } \\
(n=10)\end{array}$} & \multicolumn{4}{|c|}{ JNJ-54452840 } \\
\hline & & $\begin{array}{l}20 \mathrm{mg} \\
(\mathrm{n}=8)\end{array}$ & $\begin{array}{l}80 \mathrm{mg} \\
(\mathrm{n}=6)\end{array}$ & $\begin{array}{l}160 \mathrm{mg} \\
(\mathrm{n}=12)\end{array}$ & $\begin{array}{l}\text { Combined } \\
(n=26)\end{array}$ \\
\hline \multicolumn{6}{|l|}{ Local LVEF, \% } \\
\hline Baseline, mean (SD) & $32.6(5.8)$ & $33.6(9.8)$ & $35.3(8.6)$ & $32.5(9.3)$ & $33.5(9.0)$ \\
\hline $\begin{array}{l}\text { Change from baseline to month } 9 \text {, } \\
\text { mean (SD) }\end{array}$ & $-0.8(4.4)$ & $-1.9(6.0)$ & $3.8(4.0)$ & $-1.8(3.1)$ & $-0.5(4.9)$ \\
\hline \multicolumn{6}{|c|}{ 6-minute walk test, meters mean (SD) } \\
\hline Baseline & $421(113)$ & $451(51)$ & $395(81)$ & $421(110)$ & $425(87)$ \\
\hline $\begin{array}{l}\text { Change from baseline to month } 6 \text {, } \\
\text { meters }\end{array}$ & $38.7(63.11)$ & $-8.7(104.35)$ & $12.8(57.70)$ & $2.4(41.01)$ & $1.2(67.32)$ \\
\hline \multicolumn{6}{|l|}{ NT-proBNP, pg/ml } \\
\hline Baseline, median & 5753 & 7638 & 6933 & 7604 & 7370 \\
\hline Q1-Q3 & $5580-9556$ & $6221-8080$ & $6271-7269$ & $6513-8070$ & $6271-8008$ \\
\hline $\begin{array}{l}\text { Change from baseline to month } 6 \text {, } \\
\text { Median }\end{array}$ & -0.155 & 0.000 & 0.381 & 0.074 & 0.074 \\
\hline Q1-Q3 & $-0.323--0.145$ & $-0.142-0.418$ & $0.133-0.515$ & $0.000-0.248$ & $-0.015-0.390$ \\
\hline
\end{tabular}

LVEF: Left Ventricular Ejection Fraction; NT-proBNP: N-terminal pro-hormone B-type Natriuretic Peptide.

Table 2B: Changes from baseline in secondary efficacy endpoints (Intent-to-treat population)

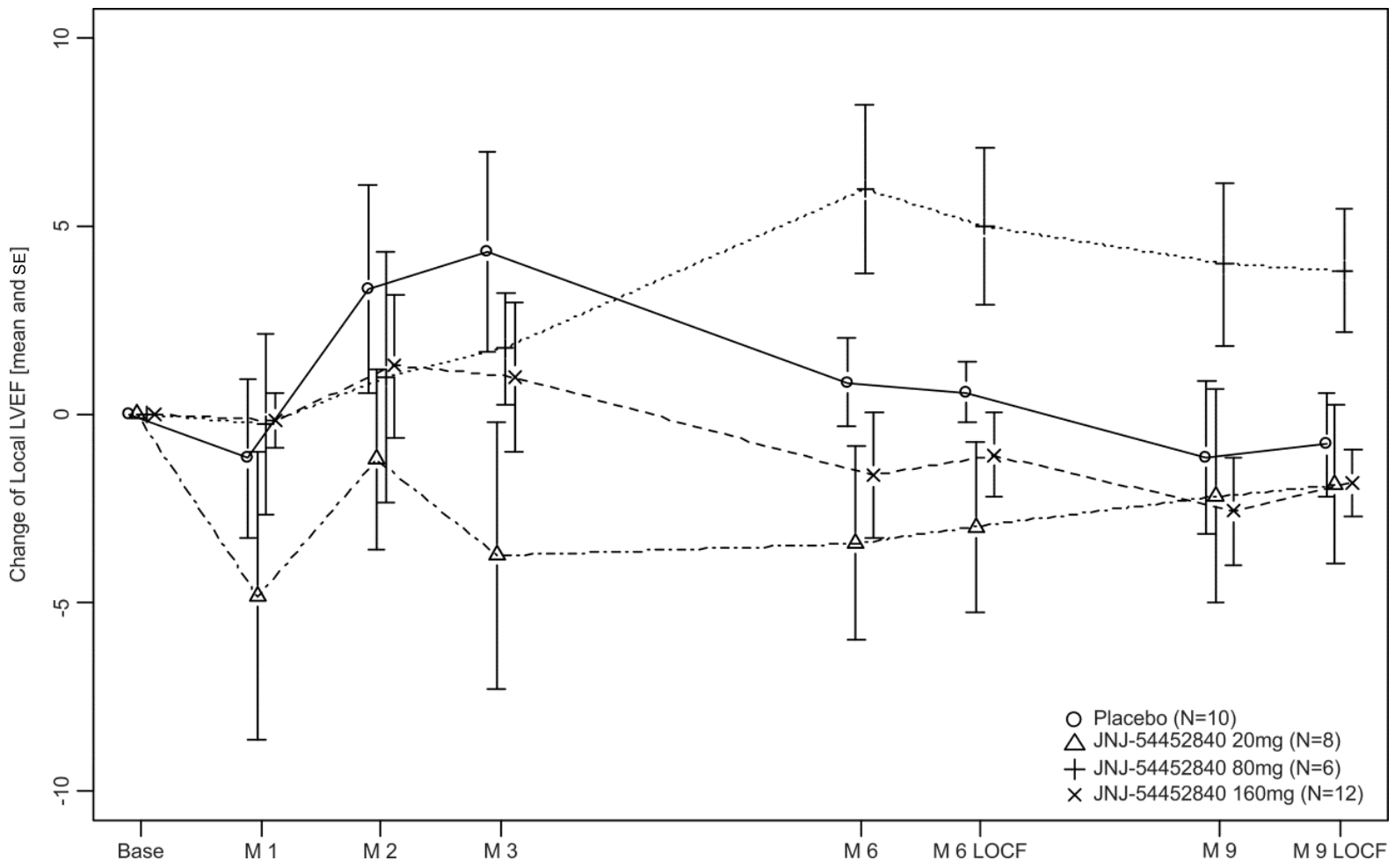

ITT: Intent-to-Treat; LOCF: Last Observation Carried Forward; LVEF: Left Ventricular Ejection Fraction; SE: Standard Error.

Figure 2: Mean (SE) change from baseline over time in local left ventricular ejection fraction (ITT population). 
Citation: Störk S, Plotnikov AN, Peters G, Davies BE, Nnane I, et al. (2016) Effects of JNJ-54452840, an Anti- 31 Receptor Antibody Cyclopeptide in Heart Failure Patients: A Randomized, Double-blind, Parallel-group, Phase-2 Pilot Study. Cardiovasc Pharm Open Access 5: 190. doi:10.4172/2329-6607.1000190

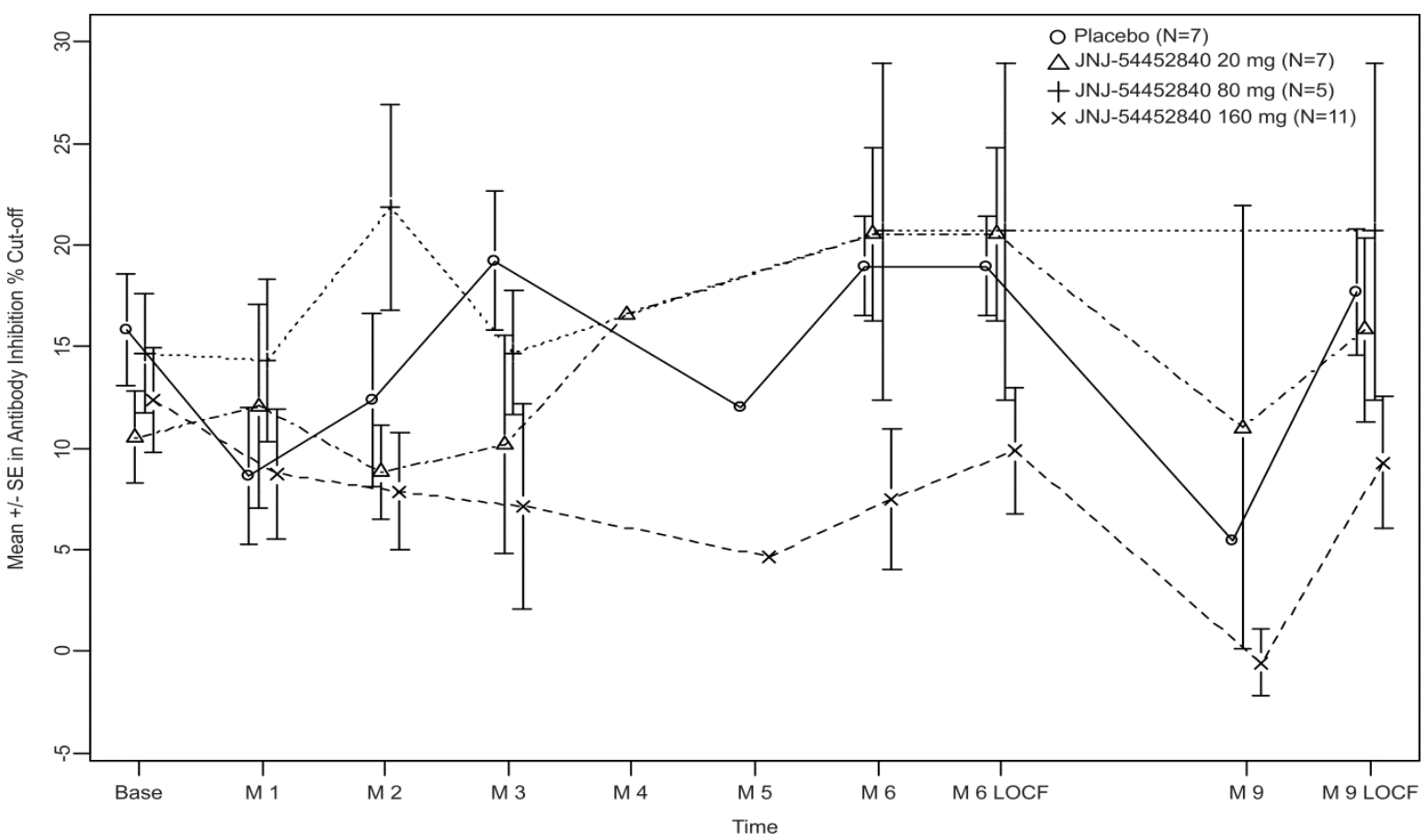

AR: Adrenergic Receptor; LOCF: Last Observation Carried Forward; SE: Standard Error

Figure 3: Mean (SE) $\beta_{1}$-AR autoantibody over time (Safety population).

patients were observed to have undetectable autoantibody levels at any study-time after receiving the first JNJ-54452840 dose: placebo $(n=2)$ and $80 \mathrm{mg}(\mathrm{n}=1)$ at one time-point, $20 \mathrm{mg}(\mathrm{n}=1)$ at two time-points, $160 \mathrm{mg}(\mathrm{n}=1)$ at three time-points, and $(\mathrm{n}=3)$ at one time-point each.

\section{Pharmacokinetics (PK)}

Mean plasma JNJ-54452840 concentrations peaked at 2 minutes following the first infusion on day 1 and at the month 5 last infusion, and then declined bi-exponentially for all treatment groups (Figure 4). Accumulation of plasma concentrations of JNJ-54452840 did not occur in any of the treatment groups after monthly intravenous infusion of JNJ-54452840. Mean $\mathrm{C}_{\max }$ and AUC values increased with escalating dose in a more than dose-proportional manner. However, the limited number of patients evaluable for PK data precludes any definitive conclusions regarding dose-proportionality. After the first dose, JNJ54452840 terminal $t_{1 / 2}$ was short (mean range: 9.35-11.62 minutes), and clearance (CL) was rapid (mean range: $1061-1700 \mathrm{~mL} / \mathrm{min}$ ), mean residence time (MRT) values ranged from 9.12-11 minutes across all dose groups. The mean volume of distribution $\left(\mathrm{V}_{\mathrm{ss}}\right)$ values ranged from 9.8-17.4 $\mathrm{L}$ across all dose groups indicating that the distribution of JNJ54452840 may not be limited to the vascular compartment, but also include the extracellular space. Mean CL, $\mathrm{V}_{\mathrm{ss}}, \mathrm{T}_{1 / 2}$, and MRT values after the last infusion were generally similar to those obtained after first infusion of JNJ-54452840. There was a general trend for mean CL and $\mathrm{V}_{\mathrm{ss}}$ to decrease, while mean $\mathrm{t}_{1 / 2}$ and MRT remained similar when the dose of JNJ-54452840 was increased from $20 \mathrm{mg}$ to $160 \mathrm{mg}$ in these heart failure patients.

\section{Safety}

Most of the patients (placebo: $57.1 \%$, total JNJ-54452840 group: $87 \%$ ) in all treatment groups experienced at least one TEAE, with numerically more events reported in JNJ-54452840-treated patients
(Table 3). Overall, the most common ( $\geq 3$ patients) TEAEs in the JNJ54452840-treated groups were cardiac failure and nasopharyngitis $(\mathrm{n}=4$ each), and cough, sinusitis, and increased heart rate $(\mathrm{n}=3$ each). One patient each from the placebo, $20 \mathrm{mg}$ and $80 \mathrm{mg}$ groups reported an SAE, with more events in the high-dose $(160 \mathrm{mg})$ group $(\mathrm{n}=6)$ than any other dose group. TEAEs led to treatment discontinuation for 2 patients from the $20 \mathrm{mg}, 1$ patient from the $80 \mathrm{mg}, 3$ patients from the $160 \mathrm{mg}$, and none in the placebo group. One death due to cardiogenic shock (160 mg group) occurred during the study. Bradyarrhythmia was reported in two patients (one each in the $20 \mathrm{mg}$ and $160 \mathrm{mg}$ groups). Five patients had peripheral edema and one patient reported obstructive airway disorder, but none of these events were felt by the investigator to be immune or allergic reactions.

\section{Discussion}

Circulating anti- $\beta 1$-Abs are thought to contribute to worsening of the clinical course of progressive cardiac dilatation and failure $[3,4,16$ 19], and have been shown to be associated with an approximate threefold increased risk for cardiovascular death in DCM patients that may not be fully ameliorated with conventional cardio-selective $\beta$-blocker therapy $[3,4]$. Thus, specific anti- $\beta 1$-Ab-directed therapy can likely be a novel target for the treatment of such patients or for the treatment of refractory DCM [20]. Addressing this question, two studies have investigated JNJ-54452840, a novel approach to decrease circulating anti- $\beta 1$-Abs.

JNJ-54452840 has demonstrated a dose-related pharmacodynamic response of binding inhibition of $\beta 1$-AR Abs in standardized test plasma samples gleaned during a phase 1 study in healthy volunteers [12]. The compound was well-tolerated, and emergence of anti- $\beta 1$-AR-Abs was not observed [12]. In the current phase 2 pilot study, a relevant increase in LVEF (central assessment) was observed in several of those patients who received either $80 \mathrm{mg}$ or $160 \mathrm{mg}$ JNJ-54452840 in addition to guideline- 
Citation: Störk S, Plotnikov AN, Peters G, Davies BE, Nnane I, et al. (2016) Effects of JNJ-54452840, an Anti- 31 Receptor Antibody Cyclopeptide in Heart Failure Patients: A Randomized, Double-blind, Parallel-group, Phase-2 Pilot Study. Cardiovasc Pharm Open Access 5: 190. doi:10.4172/2329-6607.1000190

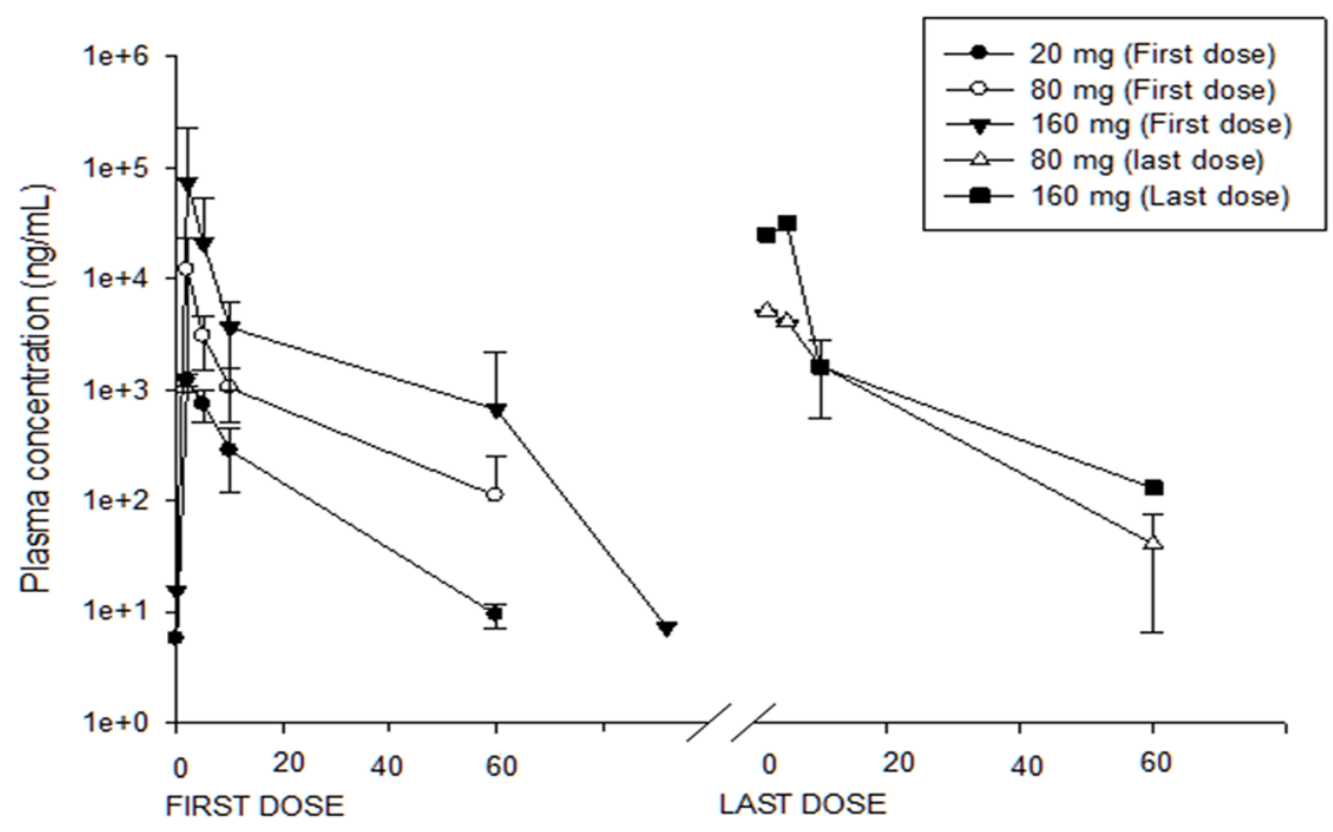

Time (minutes)

\begin{tabular}{|c|c|c|c|c|c|c|}
\hline \multirow[b]{2}{*}{ Parameters } & \multicolumn{3}{|c|}{ First dose } & \multicolumn{3}{|c|}{ Last dose $\left(6^{\text {tn }}\right.$ Dose $)$} \\
\hline & $20 \mathrm{mg}$ & $80 \mathrm{mg}$ & $160 \mathrm{mg}$ & $20 \mathrm{mg}$ & $80 \mathrm{mg}$ & $\star 160 \mathrm{mg}$ \\
\hline $\mathrm{C}_{\max }(\mathrm{ng} / \mathrm{mL})$ & $1235(166)$ & $\begin{array}{c}11988 \\
(11040)\end{array}$ & $\begin{array}{c}74165 \\
(154165)\end{array}$ & $\mathrm{NA}$ & $5180(119)$ & 31665 (NA) \\
\hline $\begin{array}{l}\mathrm{AUC}_{3} \\
(\mu \mathrm{g} \cdot \text { day } / \mathrm{ml})\end{array}$ & $\begin{array}{r}12370 \\
(3857)\end{array}$ & $\begin{array}{c}93682 \\
(88949)\end{array}$ & $\begin{array}{l}137716 \\
(36446)\end{array}$ & NA & $\begin{array}{c}60734 \\
(20813)\end{array}$ & NA \\
\hline $\begin{array}{l}\mathrm{CL} / \mathrm{F}(\mathrm{mL} / \mathrm{min}) \\
\mathrm{Vss}(\mathrm{mL})\end{array}$ & $\begin{array}{c}1700(530) \\
17366 \\
(3626)\end{array}$ & $\begin{array}{c}1555(1476) \\
16752 \\
(21329)\end{array}$ & $\begin{array}{c}1229(307) \\
11326(3523)\end{array}$ & $\begin{array}{l}\text { NA } \\
\text { NA }\end{array}$ & $\begin{array}{c}1399(480) \\
13946(300)\end{array}$ & $\begin{array}{l}\text { NA } \\
\text { NA }\end{array}$ \\
\hline $\begin{array}{l}T_{1 / 2}(\min ) \\
M R T(\min )\end{array}$ & $\begin{array}{c}9.35(0.47) \\
10.39(1.10)\end{array}$ & $\begin{array}{l}9.83(1.80) \\
7.76(6.35)\end{array}$ & $\begin{array}{l}8.81(1.23) \\
9.19(1.42)\end{array}$ & $\begin{array}{l}\text { NA } \\
\text { NA }\end{array}$ & $\begin{array}{c}8.25(1.4) \\
10.55(3.4)\end{array}$ & $\begin{array}{l}\text { NA } \\
\text { NA }\end{array}$ \\
\hline
\end{tabular}

${ }^{*} t_{1 / 2}, M R T, C L, V_{s s}$, and $A \cup C_{\text {inf }}$ were not calculated because $R_{\text {sq }}$ (adjusted) $<0.90$

AUC : Area under the plasma concentration-time curve from time 0 to infinite time; $\mathrm{C}_{\mathrm{ma}}$ : Maximum plasma concentration; CL/F: Total plasma clearance; MRT: Mean residence time; $\mathrm{T}_{1 / 2}:$ Terminal half-life; $\mathrm{V}_{\mathrm{ss}}$ : Volume of distribution at steady state

Figure 4: Mean plasma concentrations of JNJ-54452840 after repeated monthly intravenous administration.

\begin{tabular}{|c|c|c|c|c|c|}
\hline & \multirow{2}{*}{$\begin{array}{c}\text { Placebo } \\
(n=7) \\
n\end{array}$} & \multicolumn{4}{|c|}{ JNJ-54452840 } \\
\hline & & $\begin{array}{c}20 \mathrm{mg} \\
(\mathrm{n}=7) \\
\mathrm{n}\end{array}$ & $\begin{array}{c}80 \mathrm{mg} \\
(\mathrm{n}=5) \\
\mathrm{n}\end{array}$ & $\begin{array}{c}160 \mathrm{mg} \\
(\mathrm{n}=11) \\
\mathrm{n}\end{array}$ & $\begin{array}{c}\text { Combined } \\
(n=23) \\
n\end{array}$ \\
\hline $\begin{array}{l}\text { Total no. of patients with } \\
\text { TEAEs }\end{array}$ & 4 & 7 & 5 & 8 & 20 \\
\hline Nasopharyngitis & 0 & 1 & 2 & 1 & 4 \\
\hline Cardiac failure & 1 & 1 & 1 & 2 & 4 \\
\hline $\begin{array}{l}\text { Serum potassium } \\
\text { increased }\end{array}$ & 0 & 1 & 0 & 1 & 2 \\
\hline Cough & 0 & 1 & 0 & 2 & 3 \\
\hline Diarrhea & 0 & 0 & 0 & 2 & 2 \\
\hline Heart rate increased & 1 & 1 & 1 & 1 & 3 \\
\hline Nausea & 1 & 1 & 0 & 1 & 2 \\
\hline Peripheral edema & 1 & 0 & 2 & 0 & 2 \\
\hline Pre-syncope & 0 & 0 & 1 & 1 & 2 \\
\hline Pyrexia & 1 & 0 & 1 & 1 & 2 \\
\hline Sinusitis & 0 & 1 & 1 & 1 & 3 \\
\hline
\end{tabular}

TEAE: Treatment-Emergent Adverse Events.

Table 3: Treatment-emergent adverse events in at least 2 patients in $\mathrm{JNJ}$ 54452840 combined treatment group (Safety population) recommended heart failure therapy. With $80 \mathrm{mg}$ of JNJ-54452840 dose, the mean LVEF increased by $5.4 \%$, whereas it decreased by $1.6 \%$ in the placebo-treated group. A statistically significant change in mean EF cannot be expected in the small group size of only 17 patients who were treated according to the protocol. Most notably, secondary efficacy endpoints generally paralleled with the primary endpoint. In the $80 \mathrm{mg}$ group, an increase in LVEF over time (local assessment) was observed, although not sustained beyond month 6 . Little clinical improvement was observed in JNJ-54452840-treated patients.

Aberrant immune activation was not observed either in the previous (healthy volunteer) [12] or in the current study in heart failure patients receiving JNJ-54452840. Hemodynamic effects such as worsening of cardiac failure or increased heart rate were observed more often in patients treated with JNJ-54452840 than in those patients who received placebo, although in this study JNJ-54452840 was generally well-tolerated, and its safety profile was similar to that observed in the general heart failure population.

Plasma concentrations of JNJ-54452840 increased greater than dose-proportionally in the present study in heart failure patients. In 
Citation: Störk S, Plotnikov AN, Peters G, Davies BE, Nnane I, et al. (2016) Effects of JNJ-54452840, an Anti- 31 Receptor Antibody Cyclopeptide in Heart Failure Patients: A Randomized, Double-blind, Parallel-group, Phase-2 Pilot Study. Cardiovasc Pharm Open Access 5: 190. doi:10.4172/2329-6607.1000190

contrast, in a previous study with healthy volunteers, the plasma JNJ54452840 concentration increased linearly with the administered dose [12]. However, consistency was observed for short half-life and rapid clearance after intravenous infusion of JNJ-54452840 in both healthy volunteers and heart failure patients [12]. Moreover, the distribution of JNJ-54452840 appeared not only to be limited to the vascular compartment, but also to diffuse into the extracellular space.

The current pilot study is limited by a small sample size. To generate sufficient data to determine optimal dose and treatment intervals for JNJ-54452840 (previously COR-1), additional dose finding investigation was required in an extended population. As it was determined that the originally conceived study would not be able to accomplish its original objectives, considering that 100 patients per dose-group were estimated to be required for a definitive dose-efficacy study, the original protocol was amended to a pilot study in order to generate important information for the planning of a definitive dose-finding study.

Other limitations of this study include the high treatment discontinuation rate and that one of the key inclusion criterion for study entry entailed the presence of circulating anti- $\beta 1$-Abs. Despite the ability of the assay to detect a significantly higher frequency of circulating anti- $\beta 1$-Abs in heart failure patients compared with the healthy population [15], its non-quantitative validation, along with its low sensitivity and rather high variability, also challenge drawing definitive conclusions about response to treatment with JNJ-54452840.

\section{Conclusion}

Considering the limited power of this pilot study, no definitive statements can be made on the efficacy of treatment with intravenous once-monthly JNJ-54452840 in DCM patients with circulating anti- $\beta 1$ AR antibodies versus placebo in addition to guideline-recommended heart failure therapy. No compound-related safety or tolerability signals were observed.

\section{Acknowledgments}

The authors are most grateful to the study participants for their contributions and the investigational staff for the medical care. The authors acknowledge Ashwin Patil, MS, ISMPP CMPPTM (SIRO Clinpharm Pvt. Ltd.) for medical writing assistance (funded by Janssen Research and Development, LLC), and Bradford Challis, PhD, MBA (Janssen Research \& Development, LLC) for additional editorial support.

\section{Study Support}

Funded by Janssen Research \& Development, LLC, New Jersey, USA. The sponsor also provided a formal review of this manuscript.

\section{Registration}

The study is registered at ClinicalTrials.gov: NCT01391507.

\section{Conflict of Interest/Disclosures}

Drs. Störk, Kääb, Bauer, Luchner and Ertl designed the study and declare no conflict of interest. Drs. Jahns, Lohse and Ungerer are former shareholders of Corimmun, which was sold to Janssen Research \& Development, and would participate upon further development of the project. Drs. Plotnikov, Peters, Davies, Tesfaye, Rivas and Nnane were responsible for data collection and analysis. Drs. Plotnikov, Peters, Davies, Rivas, Tesfaye and Nnane are employees of Janssen Research \& Development, LLC, and own stock/stock options in Johnson \& Johnson.

All authors met ICMJE criteria and all those who fulfilled those criteria are listed as authors. All authors had access to the study data, provided direction and comments on the manuscript, made the final decision about where to publish these data and approved the final draft and submission to this journal.

\section{References}

1. Lloyd-Jones D, Adams R, Carnethon M, De Simone G, Ferguson TB, et al. (2009) Heart disease and stroke statistics--2009 update: a report from the American Heart Association Statistics Committee and Stroke Statistics Subcommittee. Circulation 119: 480-486.
2. Patel PA, Hernandez AF (2013) Targeting anti-beta-1-adrenergic receptor antibodies for dilated cardiomyopathy. Eur J Heart Fail 15:724-729.

3. Stork S, Boivin V, Horf R, Hein L, Lohse MJ, et al. (2006) Stimulating autoantibodies directed against the cardiac beta1-adrenergic receptor predict increased mortality in idiopathic cardiomyopathy. American heart Journal 152: 697-704.

4. Jahns R, Boivin V, Siegmund C, Inselmann G, Lohse MJ, et al. (1999) Autoantibodies activating human beta1-adrenergic receptors are associated with reduced cardiac function in chronic heart failure. Circulation 99: 649-654.

5. Iwata M, Yoshikawa T, Baba A, Anzai T, Mitamura H, et al. (2001) Autoantibodies against the second extracellular loop of beta1-adrenergic receptors predict ventricular tachycardia and sudden death in patients with idiopathic dilated cardiomyopathy. J Am Coll Cardiol 37: 418-424.

6. Nikolaev VO, Boivin V, Stork S, Angermann CE, Ertl G, et al. (2007) A novel fluorescence method for the rapid detection of functional beta1-adrenergic receptor autoantibodies in heart failure. J Am Coll Cardiol 50: 423-431.

7. Boivin VHL, Angermann CE (2005) A novel receptor-homologous cyclic peptide prevents $ß 1$-adrenoceptor antibody-induced progressive cardiomyopathy. Eur J Heart Fail 4: 104

8. Jahns R, Boivin V, Lohse MJ (2006) beta (1)-Adrenergic receptor function, autoimmunity, and pathogenesis of dilated cardiomyopathy. Trends in Cardiovascular Medicine 16: 20-24.

9. Jahns R, Schlipp A, Boivin V, Lohse MJ (2010) Targeting receptor antibodies in immune cardiomyopathy. Semin Thromb Hemost 36: 212-218.

10. Boivin V, Beyersdorf N, Palm D, Nikolaev VO, Schlipp A, et al. (2015) Novel ReceptorDerived Cyclopeptides to Treat Heart Failure Caused by Anti-beta1-Adrenoceptor Antibodies in a Human-Analogous Rat Model. PloS One 10: e0117589.

11. McMurray JJ, Adamopoulos S, Anker SD, Auricchio A, Bohm M, et al. (2012) ESC Guidelines for the diagnosis and treatment of acute and chronic heart failure 2012: The Task Force for the Diagnosis and Treatment of Acute and Chronic Heart Failure 2012 of the European Society of Cardiology. Developed in collaboration with the Heart Failure Association (HFA) of the ESC. Eur Heart J 33: 1787-1847

12. Munch G, Boivin-Jahns V, Holthoff HP, Adler K, Lappo M, et al. (2012) Administration of the cyclic peptide COR-1 in humans (phase I study): ex vivo measurements of anti-beta1-adrenergic receptor antibody neutralization and of immune parameters. Eur J Heart Fail 14: 1230-1239.

13. Cintron G, Johnson G, Francis G, Cobb F, Cohn JN (1993) Prognostic significance of serial changes in left ventricular ejection fraction in patients with congestive heart failure. The V-HeFT VA Cooperative Studies Group. Circulation 87: VI17-V23.

14. Kramer DG, Trikalinos TA, Kent DM, Antonopoulos GV, Konstam MA, et al. (2010) Quantitative evaluation of drug or device effects on ventricular remodeling as predictors of therapeutic effects on mortality in patients with heart failure and reduced ejection fraction: a meta-analytic approach. J Am Coll Cardiol 56: 392-406.

15. Holthoff HP, Zeibig S, Jahns-Boivin V, Bauer J, Lohse MJ, et al. (2012) Detection of anti-beta1-AR autoantibodies in heart failure by a cell-based competition ELISA. Circulation Research 111: 675-684.

16. Jahns R, Boivin V, Hein L, Triebel S, Angermann CE, et al. (2004) Direct evidence for a beta 1-adrenergic receptor-directed autoimmune attack as a cause of idiopathic dilated cardiomyopathy. J Clin Invest 113: 1419-1429.

17. Jahns R, Boivin V, Siegmund C, Boege F, Lohse MJ, et al. (1999) Activating beta-1-adrenoceptor antibodies are not associated with cardiomyopathies secondary to valvular or hypertensive heart disease. J Am Coll Cardiol 34: 1545-1551.

18. Wallukat G, Reinke P, Dorffel WV, Luther HP, Bestvater K, et al. (1996) Removal of autoantibodies in dilated cardiomyopathy by immunoadsorption. Int J Cardiol 54: 191-195.

19. Wallukat G, Wollenberger A, Morwinski R, Pitschner HF (1995) Anti-beta 1 -adrenoceptor autoantibodies with chronotropic activity from the serum of patients with dilated cardiomyopathy: mapping of epitopes in the first and second extracellular loops. J Mol Cell Cardiol 27: 397-406.

20. Nussinovitch $U$, Shoenfeld $Y$ (2013) The clinical significance of anti-beta-1 adrenergic receptor autoantibodies in cardiac disease. Clinical Rev Allerg Immunol 44: 75-83. 